\title{
Food Security in a Regional Area of Australia: A Socio-economic Perspective
}

\author{
Quynh Lề ${ }^{1, *}$, Stuart Auckland ${ }^{1}$, Hoang Boi Nguyen ${ }^{1}$, Sandra Murray $^{1}$, Gretchen Long ${ }^{2}$, Daniel R Terry ${ }^{3}$ \\ ${ }^{1}$ University of Tasmania, Australia \\ ${ }^{2}$ North East Scottsdale Memorial Hospital, Scottsdale, Tasmania, Australia \\ ${ }^{3}$ University of Melbourne, Australia \\ *Corresponding Author: Quynh.Le@utas.edu.au
}

Copyright (C) 2014 Horizon Research Publishing All rights reserved.

\begin{abstract}
While Australia is considered to be a highly food-secure nation, some populations are more vulnerable to food insecurity than others and this applies to Tasmania, an island state of Australia. The aim of this study was to highlight food security issues in the two local government areas of Dorset and Clarence in Tasmania, Australia. This paper reports on the key quantitative findings of the project with a focus on food access and food utilisation, and their association with socio-economic factors. Quantitative data were collected from a total of 835 survey participants using a questionnaire developed in close consultation with service provider organizations as well as public health and nutrition experts. The study revealed $53(6.6 \%)$ residents were at the low food security and $18(2.1 \%)$ who literally went without food. The significant correlations between low food security and socio-economic factors evidenced in the study further suggested that the low-food security residents were more likely to come from the more vulnerable groups of low income families $(\chi 2=42.528, \mathrm{df}=6, \mathrm{p}<0.05)$, the younger and older population groups $(\chi 2=12.361, \mathrm{df}=5, \mathrm{p}<0.05)$ or those living in socio-economically disadvantaged rural areas $(\chi 2=165.9$, df $=7, \mathrm{p}<0.05)$. A link between physical and financial access was clearly indicated due to high fuel cost $(44.4 \%)$ which was the most common barrier reported among those who used personal vehicles for travelling to and from food shops. The study findings help to direct strategic policies to food security for the future of Tasmanians such as the "Food for all Tasmanians" strategy by the Tasmanian Food Security Council which focuses on ensuring social food equity for all Tasmanians. These strategies include promoting publicly funded community cars, promoting local produce and food access initiatives such as increased farm gate sales, farmer markets, food cooperatives, community gardens and growing and swapping produce within communities.
\end{abstract}

Keywords Determinants, Food Security, Socioeconomic Status, Vulnerable Groups

\section{Introduction}

Food security has officially been recognised as a global issue since the 1996 World Food Summit, wherein it was defined as a situation that "exist when all people, at all times, have physical social and economic access to sufficient safe and nutritious food that meets their dietary needs and food preferences for an active and healthy life" [1]. On the other hand, food insecurity exists when people do not have adequate physical, social or economic access to food as defined above [2]. The terms 'food security' and 'food insecurity' are often used interchangeably in some contexts. In this paper, the term 'food security' is used in its generic sense to broadly cover this dichotomy; whereas food insecurity is only used to refer specifically to low food security, or lack of it.

Food security is most commonly conceptualised as dependent on four aspects of availability, access, utilisation and stability $[3,4]$. Food availability refers to the range of nutritious foods such as fresh fruits and vegetables which are sold or served at local food outlets while food access indicates the extent to which individuals are physically and economically capable in obtaining nutritious foods $[5,6]$. Food availability and food access then interact to influence food utilisation which is defined as the appropriate use of food, based on knowledge of basic nutrition and care [7]. Food stability refers to the ability to obtain food over time. In transitory stages, food may be unavailable during certain periods of time; whereas natural disasters result in crop failure and decreased food availability at the food production level. In addition, civil conflicts can also reduce access to food [4]. Other factors that can temporarily cause food insecurity are loss of employment or productivity, which can be caused by illness. Seasonal food insecurity can result from the regular pattern of growing seasons in food production [8].

Food security is closely connected with other important socio-economic issues. In particular, there is a strong link between food security and neighborhood socio-economic characteristics, such as educational attainment, employment 
rates and income [9-12].

Research efforts at different levels have been made to examine food security disparities between socio-economically advantaged and disadvantaged groups in Australia and other developed countries [13-15]. For example, in the US, the prevalence of food insecurity was $11.2 \%$ of households, which rose to $14.6 \%$ in 2008 . In addition, $3.5 \%$ of all households experienced hunger in 2003 and this figure rose to $5.7 \%$ in 2008 . Notably, the greatest food security challenges occurred among populations with children in low income, single parent, African-American and Hispanic households in the South and West of the country [16].

In Australia, a highly food-secure nation, there is also evidence that many Australians encounter physical and financial constraints to the daily access of nutritious foods [17-20]. For example, the 2006 Victorian Population Health Survey indicated $3.6 \%$ of two-parent families and $20.6 \%$ of one-parent families (both with dependent children) had, in the previous year, run out of food and had no money to buy more [21]. Similar to the US, groups such as the unemployed, single parent households, low-income earners, rental households and young people are more vulnerable to food insecurity. In addition, low-income households and those in remote areas, are less likely to consume the recommended intake of fruit and vegetables per day [22-25].

Tasmania has been reported to have a higher level of socioeconomic disadvantage compared to other states of Australia. The unemployment rates in Tasmania (6.4\%) were reported to be slightly higher than the national levels (5.6\%) [26]. Regarding educational attainment, Tasmania has a low level of working age persons who have attained a bachelor degree or higher (11.8\% as opposed to $14.3 \%$ for Australia) [27]. In addition, the median weekly personal income for people aged 15 years and over in Tasmania was \$AUS 499 which was lower than national average (\$AUS 577) [27]. According to the Australian Bureau of Statistics [28], 20 out of 29 of the Local Government Areas (LGAs) in Tasmania Socio-economic Indexes for Areas (SEIFA) fall into a score between deciles 1 and 4 . This demonstrates that 20 of the 29 LGAs of Tasmania are in $40 \%$ of the most disadvantaged areas of Australia. Due to higher socio-economic disadvantage level in Tasmania, food insecurity threatens a proportionately higher number of people than the national average..

In terms of food supply, the overall cost, identified within the Healthy Food Access Basket survey (HFAB), is regularly $30 \%$ higher in remote and rural areas than in major cities [29, 30 ]. Furthermore, about $10 \%$ of the HFAB food items may not be available for purchase in remote and very remote areas [29]. Similarly, McCluskey [17] reported that very few residents in the City of Moreland, Victoria, were within $400 \mathrm{~m}$ of a fresh fruit and vegetable outlet and that there were price variances across Moreland, with some areas where they were $25 \%$ above the average. These findings underscore the disparity in food availability and access between metropolitan areas and areas of varying remoteness.
Discrepancies in healthy food availability and access have also been confirmed in South Australia, Western Australia and the Northern Territory. The 2000 Food Supply in Rural South Australia study showed evidence of higher prices and fewer varieties of foods for people living outside Adelaide and other large regional centers [31]. In Western Australia, the Food Access and Costs Survey indicated that food prices, food access and food quality were closely related to geographic location, in favor of socio-economically advantaged areas. Importantly, healthier foods were found to exhibit the greatest difference, with costs of fruit, vegetables and dairy standing at $32 \%, 26 \%$ and $40 \%$, respectively, higher in remote areas [32]. In the Northern Territory, the cost of the food basket in remote stores was found to be $23 \%$ more expensive than in Darwin supermarkets, and 19\% more expensive than Darwin corner stores. In terms of food availability, about $7 \%$ of the items in the food basket were not available in the remote stores surveyed [33]

In Tasmania, research evidence consistently reflects the national trends. A report by Madden [34] on the casualisation of work in Tasmania revealed patterns of food shortage among people who were underemployed. In another study of clients of emergency relief and financial counseling services around Tasmania in 2003, Madden [35] found that $59 \%$ of the respondents had gone without meals in the past year due to financial hardship and that $70 \%$ of respondents always or almost always worried about whether the amount of food they could buy for their household would be enough.

While efforts have been made to improve food security in Tasmania, particularly through the initial establishment of the Tasmanian Food Security Council in 2009; the implementation of the Tasmanian Food and Nutrition Policy in 2004 [36]; and the 2012 Tasmanian Food Security Strategy [37], there is a scarcity of data on the levels and extent of food security in this regional state. This is especially in relation to socio-economic factors. Therefore, this study was aimed at examining two major determinants of food security, food access and food utilisation, and their association with social-economic factors.

\section{Methods}

\subsection{Study Design and Setting}

A community-based mixed methods project using a combination of quantitative and qualitative approaches was conducted in this study. The project was funded through the Tasmanian Food Security Council which was established by a coalition of stakeholder organisations and was known as the Tasmanian Food Access Research Coalition (TFARC). The aim of TFARC was to examine and address food security issues in the two local government areas of Dorset and Clarence. The two local government areas (LGAs) of Clarence and Dorset, Tasmania, Australia were chosen as the research sites for the Tasmanian Food Access Research 
project, the former described as urban, peri-urban and rural, and the latter classified as rural and remote, in order to contribute to a state-wide food security monitoring and evaluation system across two conditions common to Tasmania as shown in Figure 1.

Clarence (South-East of Tasmania) was selected, as it is one of the largest cities in Australia, covering 386 square km. According to the 2011 Census [38] it had a population of 51,852 people which is $10.5 \%$ of Tasmania's population. It is the second most populated city in Tasmania. Clarence is experiencing modest population growth $(2 \%$ in the period 2006 - 2011) with much of the expansion concentrated on new developments, particularly in the Clarence Plains area $[38,39]$. Some communities on the outskirts of Clarence have relatively low access to appropriate supporting infrastructure [40].

Dorset (North-East of Tasmania) was chosen as the rural/remote region in which to develop and trial the model.
Rural and remote regions within Tasmania face a range of health concerns differing from their urban counterparts. Declining and rapidly ageing populations coupled with economic decline and remoteness can make accessing health information and health promotion services a challenge. Dorset has a population of 6,827 people spread over 40 townships and population centers and covers 3,196 square kilometers, giving a population density of 2.2 people per square kilometer [38]. Dorset experienced a population decline of $5.9 \%$ in the period 2006 - 2011 and is characterised by a rapidly ageing population $[38,41]$. The area is experiencing social and economic challenges associated with the loss of industries and infrastructure such as Simplot, a vegetable processing plant, and forestry activities and, in recent years, farmers have also been affected by drought followed by flooding in agricultural areas [42]. Further data about these two study sites is shown in Table 1 below:
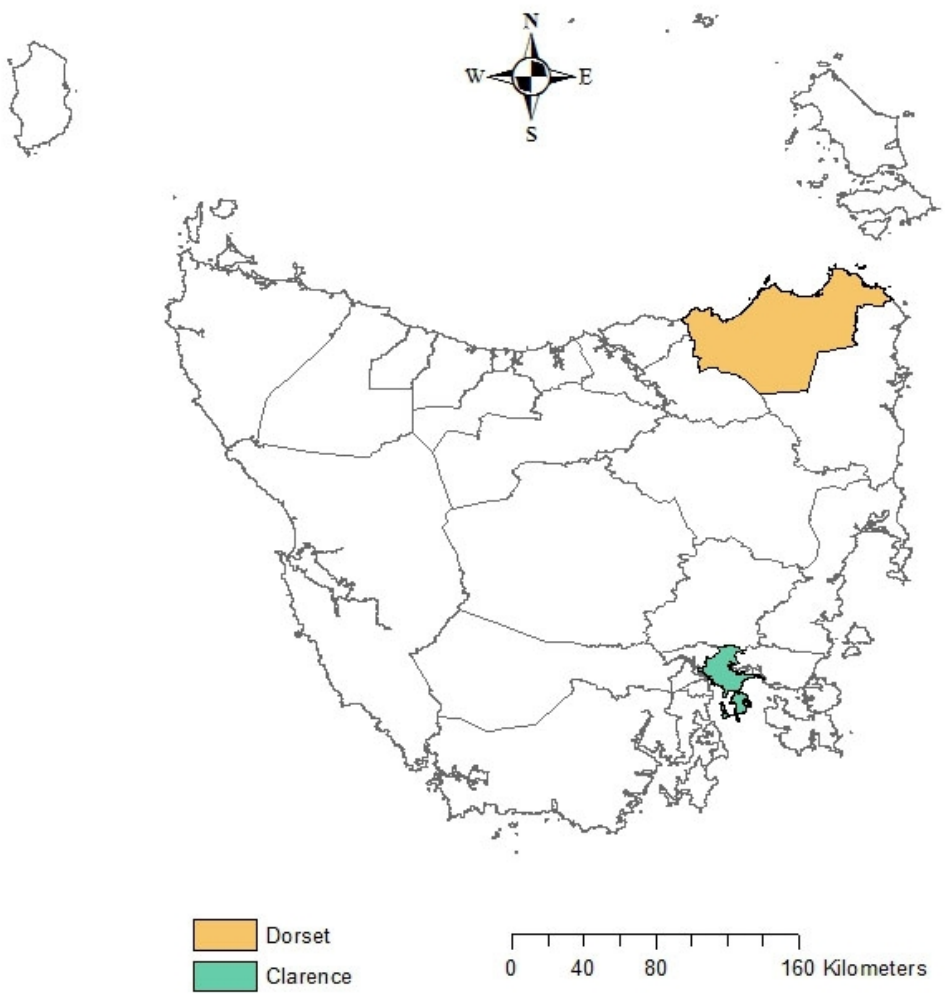

Figure 1. Location of Clarence City and Dorset LGAs

Table 1. Clarence and Dorset community profiles

\begin{tabular}{cccc}
\hline & Dorset & Clarence & Australia \\
\hline Population (persons) & 6,827 & 51,852 & $21,507,717$ \\
Median age & 44 & 41 & 37 \\
Median weekly household income (\$AUS) & 734 & 1124 & 577 \\
Median weekly individual income (\$AUS) & 393 & 577 & 5.6 \\
Unemployment rates (\%) & 9.2 & 4.9 & 14.3 \\
University or other tertiary education (\%) & 4.6 & 10.7 & NA \\
Index of Socioeconomics Disadvantage & $910 / 2$ & $988 / 7$ & \\
\hline
\end{tabular}

Source: Australian Bureau of Statistics - 2011 Census data [28, 38]. 


\subsection{Research Instrument}

The Tasmanian Household Food Security survey (THFS) was used to collect quantitative data for the study in both areas [43]. The THFS survey was constructed from a review of relevant literature, conversations with key stakeholders and consultations with an expert reference panel consisting of state and interstate experts in the field of public health and nutrition. A draft questionnaire was developed and piloted with 100 people (38 from Dorset and 62 from Clarence) recruited through the community networks and neighbourhood houses of these two study sites. Several terms were clarified such as healthy nutritious foods (recommended by health authorities) and fresh nutritious foods (e.g., fresh vegetable and fruits) [44, 45]. After appropriate revisions and modifications were made, the final survey consisted of 44 closed and open-ended questions, in which food access and food utilisation were particularly addressed. The questionnaire was designed to enhance community response and capture relevant information. It comprised five groups of questions; these were demographic data with the remaining group of questions focusing on food access, availability, affordability and awareness. Several of the demographic data questions aligned with questions from the Australian Bureau of Statistics [46]. This was considered essential as it enabled meaningful comparison with future surveys. Existing literature on food security in Tasmania is of limited use because of differences in questions and methodology used.

\subsection{Data Collection}

Data collection was conducted between May to September 2011. To increase the response rate, a lucky draw of three \$AUS 50 gift/store vouchers per study site as a prize was offered to participants who return the completed survey within two weeks since the survey distribution. A total of 835 valid responses $(79.1 \%$ response rate) to the THFS survey were collected through multiple data collection methods in Dorset and Clarence. This total figure excluded twenty one responses that were discarded because their residents were not in the targeted areas. In Dorset, the written THFS survey was distributed using stratified random sampling through local post offices within the main population centers of Bridport, Scottsdale, Ringarooma, Winnaleah and Gladstone. Prior to the distribution of the mail-out survey, it was promoted through various media, including the local newspaper, flyers, radio and school newsletters. The result was 368 validly completed surveys (73.6\% response rate) returned in this municipality.

In Clarence, through consultations with community partners, the THFS survey was conducted concurrently in the form of both hard copy and by telephone, in which the same questions were asked. As recommended by key stakeholders of the project and given the size of the population of Clarence, it was not feasible to undertake a mailed out survey of the whole municipality. Furthermore, it was anticipated a higher response rate from participants would be achieved via a telephone survey. However, a limitation of a telephone survey is that people who depend solely on mobile phones are excluded as it was conducted using landlines only. About $14 \%$ of the general population of Australia has only a mobile phone and no land line [47] and there is emerging evidence that people from lower socio-economic backgrounds are much more likely to be among those who have only a mobile phone [48]. To address this limitation, the survey was also distributed in hard copy to lower socio-economic areas.

The telephone survey randomly selected and surveyed 300 households from the Clarence municipality and was conducted through the use of a commercial population survey company. In addition, the written survey was distributed in hard copies through community events and in electronic form through the Clarence City Council and Anglicare websites. At the conclusion of the data collection process, 167 written surveys were returned, making a total of 467 responses (84\% response rate) in Clarence. Data managed by the commercial population survey company were removed from the company's server/media upon the completion of data collection. There was the potential for more than one survey to have been completed by a single person, despite clear guidelines being given not to complete the written version if the telephone version had been submitted.

\subsection{Ethics Approval}

Full ethical approval for the study was obtained by the Tasmanian Human Research Ethics Committee (HREC) Network prior to commencing the study (Ethics Ref: H0011676). The HREC Network is constituted by joint agreement between the University of Tasmania (UTAS) and the Department of Health and Human Services (DHHS). The participants took part in the research on a voluntary basis and there were no consequences if the participants decided not to participate or withdraw. In addition, to encourage a rapid response, a lucky draw with the prize of an \$AUS 50 gift/store voucher was offered for those who returned the completed questionnaires within two weeks since the survey distribution. The value of this draw was minimal. It was primarily an appreciative token and did not compromise participants' responses.

\subsection{Data Analysis}

All quantitative data from the THFS survey were coded, entered into the SPSS Software version 19, and checked for data integrity. Descriptive statistics such as frequencies, percentages, and medians were principally used to analyse the data. Inferential non-parametric tests such as Chi-square tests or loglinear analyses were also performed to determine the associations between different socio-economic factors (such as income, employment, education attainment, age groups, etc.) and aspects of food security (dependent variables). Specifically, loglinear analysis was employed 
when dealing with three or more categorical variables while a chi-square test for independence was conducted with two variables. Results were only reported where there was statistical significance at $p<=0.05$ level in the case of chi-square tests, whereas non-statistically significant results (i.e., $p>0.05$ ) were expected for assessing the overall fit of the model which was indicated in the Likelihood Ratio of loglinear analysis (i.e., the observed and expected frequencies were very similar). When appropriate, grouping of categories within a variable was conducted to meet the assumptions of loglinear analysis or chi-square tests. For example, the number of cases should be at least five times the number of cells, or all cells for two-way interactions should be greater than one and $80 \%$ should be greater than five, etc.

\section{Results}

\subsection{Socio-demographic Characteristics}

The 835 respondents to the THFS survey in the two municipalities of Dorset and Clarence differed in gender, age groups, family size, employment status and weekly income. There were a higher proportion of females to males which may have reflected those at home during the day with time to be able to respond to the survey. The age of these respondents ranged from less than 25 to over 65 years old. A high proportion of respondents ( $>50 \%)$ were 55 years old or older which reflected the typical demographic characteristic of the aging population in Tasmania. Responding to the question about current employment status, a very high proportion of respondents reported not being in the labor force. This result may be due to more than half of the survey respondents being aged 55 and over.

\subsection{Food Access}

\subsubsection{Physical Access}

Physical access to fresh nutritious foods was measured through the distance and means of travel from respondents' homes to their most frequently visited shops for food. Nearly half $(44.6 \%)$ of the respondents lived beyond $5 \mathrm{~km}$ away, among whom $25.4 \%$ were within $5-20 \mathrm{~km}$ and $19.1 \%$ more than $20 \mathrm{~km}$. The majority (89.4\%) used private vehicles as the principle means of travel, with walking and public transport accounting for $7.0 \%$ and $2.4 \%$ of respondents, respectively.

Regarding barriers to accessing food, only $9.7 \%$ of respondents indicated that it was difficult for them to get to and from food shops. Among the barriers, high fuel costs was the most frequently mentioned $(44.4 \%)$, the remaining barriers being lack of private transport $(22.2 \%)$, lack of public transport (23.5\%), physical limitations (25.9\%), and the long distance from home to food shops (22.2\%).

\subsubsection{Financial Access}

The financial capacity of the respondents was measured in the survey in terms of their ability to buy nutritious foods with their regular income and possible financial barriers to buying foods. A total of $15.1 \%$ of respondents reported being unable to buy nutritious foods at some point during the last 12 months due to a shortage of money. More importantly, in answer to the question of whether or not their family members had ever gone without food because of shortage of money in the previous 12 months, $6.6 \%$ responded in the affirmative.

\subsection{Food Utilisation}

\subsubsection{Food Consumption}

Regarding food consumption, survey respondents were asked to indicate their intake of various groups of healthy nutritious foods. The findings demonstrated the lack of a healthy and balanced diet among a proportion of the respondents. While the four main groups of food were reported to be consumed on a daily basis by the majority of the respondents, they were eaten less frequently by $11 \%$ to $27 \%$ of respondents. Up to $27.9 \%$ of the respondents did not have daily consumption of food from all food groups, while some respondents indicated that they never or rarely included some food groups in their diets.

The inadequacy of food consumption was also illustrated in the proportion of respondents (6.6\%) who reported experiencing food shortages within their households in the previous 12 months as indicated in Table 2. Further findings revealed that $11.3 \%$ went without nutritious foods on a weekly basis, $18.8 \%$ fortnightly and $17.0 \%$ monthly. Approximately $34.0 \%$ reported running out of nutritious foods 3-4 times per year and $13.2 \%$ once per year. However, the number of those who had to go without foods at various frequencies was only 53 out of $835(6.6 \%)$. These findings suggested that many members of the community required support to ensure their adequate consumption of nutritious foods.

\subsection{Associations with Social-economic Factors}

A three-way loglinear analysis was performed to determine a hierarchical unsaturated model for the associations between age groups, family weekly income, and their difficulties in getting to and from shops. There were 792 participants who responded with all cells having greater than five expected frequencies. The likelihood ratio of this model was $\chi^{2}=23.204, \mathrm{df}=30, \mathrm{p}=0.807>0$. This produced a model that included main effects of three two-way associations of (family weekly income)*(difficulties in getting to and from shops), (age groups)*(family weekly income), and (age groups)*(family weekly income). Partial likelihood ratio $\chi^{2}$ are presented in Table 3 below:

A significant correlation was found between the respondents' family weekly income and their difficulties in getting to and from food shops $\left(\chi^{2}=42.528, \mathrm{df}=6, \mathrm{p}<0.05\right)$. Respondents' age groups were also significantly associated with their family weekly income $\left(\chi^{2}=122.695, \mathrm{df}=1, \mathrm{p}<0.05\right)$ 
and their difficulties in getting to and from shops $\left(\chi^{2}=12.361\right.$, $\mathrm{df}=5, \mathrm{p}<0.05$; Table 2). their difficulties in getting to and from food shops variables. Accordingly, the groups of family with lower weekly income (under \$AUS 350 or \$AUS 350 \$AUS 799 per week) were more likely to have travel difficulties compared to the groups with family incomes greater than \$AUS 799 per week ( $p$ values $<0.05$ ). Odds ratios indicated that the odds of having difficulties in getting to and from food shops of families with income under \$AUS 350 and between \$AUS 350 - \$AUS 799 per week were 7.5 and 4.7 higher, respectively, compared to families with incomes greater than \$AUS 799 per week.

Similarly, Chi-square tests were conducted on each pair of age groups and their difficulties in getting to and from food shops variables. Age groups were correlated with the reported difficulties in physical access to foods, whereby the youngest group (less than 25 years old) were more likely to have difficulty with private transport and the oldest group (over 65 years old) with physical limitations compared to other age groups ( $\mathrm{p}$ values $<0.05$ ). Odds ratios indicated that the odds of having difficulties in physical access to food of respondents who were less than 25 years old and more than 65 years old were 9.39 and 7.54, respectively and were especially higher compared to groups of $35-44$ years old and $45-54$ years old. Significant correlations were also found between age groups and financial access $\left(\chi^{2}=38.528\right.$, $\mathrm{df}=5, \mathrm{p}<0.05$ ), with the younger age groups (less than 25 years old) encountering more financial problems in buying foods.

To break down these effects, separate Chi-square tests were performed on each pair of family weekly income groups and in a comparable analysis of family income, age groups and experience of food shortages in the last 12 months, the three-way loglinear analysis produced a final model that included main effects of three two-way associations of (family weekly income)*(experience of food shortages in the last 12 months), (age groups)*(family weekly income), and (age groups)*(experience of food shortages in the last 12 months). The likelihood ratio of this model was $\chi^{2}=29.744$, $\mathrm{df}=30, \mathrm{p}=0.477>0$. Partial likelihood ratio $\chi^{2}$ are presented in Table 4.

Table 2. Frequency of food shortages and coping strategies

\begin{tabular}{cccc}
\hline & Dorset & Clarence & Total \\
\cline { 2 - 3 } Frequency of food shortage in the past 12 months & $\%(\mathrm{n})$ & $\%(\mathrm{n})$ & $\mathbf{0}(\mathrm{n})$ \\
Weekly & $\mathbf{N}=\mathbf{1 9}$ & $\mathbf{N}=\mathbf{3 4}$ & $\mathbf{N}=\mathbf{5 3}$ \\
Fortnightly & $10.5(2)$ & $11.7(4)$ & $11.3(6)$ \\
Monthly & $10.5(2)$ & $23.5(8)$ & $18.8(10)$ \\
3-4 times a year & $15.8(3)$ & $17.6(6)$ & $17.0(9)$ \\
Once a year & $42.1(8)$ & $29.4(10)$ & $34.0(18)$ \\
Other & $21.0(4)$ & $8.8(3)$ & $13.2(7)$ \\
Coping strategies in times of food shortages & $0(0)$ & $8.8(3)$ & $\mathbf{N}=\mathbf{4 3}$ \\
Skip meals & $\mathbf{N}=\mathbf{1 9}$ & $\mathbf{N}=\mathbf{2 4}$ & $41.9(18)$ \\
Reduce size of meals & $36.8(2)$ & $45.8(11)$ & $20.9(9)$ \\
Get help from family/ friends & $21.1(2)$ & $20.8(5)$ & $30.2(13)$ \\
Eat cheaper foods & $21.1(2)$ & $37.5(9)$ & $34.9(15)$ \\
Cut down on non-essentials & $42.1(2)$ & $29.2(7)$ & $30.2(13)$ \\
Cut down on nutritious food items & $26.3(2)$ & $33.3(8)$ & $18.6(8)$ \\
Grow my own fruit and vegetables & $15.8(2)$ & $20.8(5)$ & $32.6(14)$ \\
Other & $47.4(2)$ & $20.8(5)$ & $11.6(5)$ \\
\hline
\end{tabular}

Table 3. Partial associations for age groups, family weekly income, and their difficulties in getting to and from shops variables

\begin{tabular}{cccc}
\hline Effect & df & Partial Chi-square & p \\
\hline age groups*family weekly income & 1 & 122.695 & .000 \\
family weekly income*difficulties in getting to and from shops & 6 & 42.528 & .000 \\
age groups*difficulties in getting to and from shops & 5 & 12.361 & .030 \\
difficulties in getting to and from shops & 6 & 576.582 & .000 \\
age groups & 5 & 224.983 & .000 \\
family weekly income & 1 & 122.244 & .000 \\
\hline
\end{tabular}


Table 4. Partial associations for age groups, family weekly income, and their experience of food shortages in the last 12 months variables

\begin{tabular}{cccc}
\hline Effect & df & Partial Chi-square & p \\
\hline $\begin{array}{c}\text { age groups*family weekly income } \\
\text { family weekly income* experience of food shortages in the last } \\
12 \text { months }\end{array}$ & 30 & 161.682 & .000 \\
age groups*experience of food shortages in the last 12 months & 6 & 95.711 & .000 \\
family weekly income & 5 & 70.768 & .000 \\
age groups & 6 & 129.758 & .000 \\
experience of food shortages in the last 12 months & 5 & 233.404 & .000 \\
\hline
\end{tabular}

Table 4 indicates that there were significant correlations between the respondents' family weekly income and their experience of food shortages in the last 12 months $\left(\chi^{2}=\right.$ $95.711, \mathrm{df}=6, \mathrm{p}<0.05)$. Respondents' age groups were also significantly associated with their family weekly income $\left(\chi^{2}=\right.$ $161.682, \mathrm{df}=30, \mathrm{p}<0.05)$ and their experience of food shortages in the last 12 months $\left(\chi^{2}=70.768, \mathrm{df}=5, \mathrm{p}<0.05\right)$.

These effects were broken down using separate Chi-square tests at different levels for each variable. Accordingly, the younger age groups (i.e. less than 25 years old) was more likely to have experienced food shortages in the last 12 months than the older age groups (i.e. Over 65 years old $)\left(\chi^{2}=12.254, \mathrm{df}=1, \mathrm{p}=0.000<0.05\right)$. Odds ratios indicated that the odds of having experienced food shortages in the last 12 months of the youngest age group (less than 25 years old) were 5.8 higher compared to respondents aged over 65 years and the $25-34$ years group were 2.44 higher than respondents aged 45 years or older.

In particular, the groups of families with lower weekly income (under \$AUS 350 or \$AUS 350 - \$AUS 799 per week) were highly associated with food shortages compared to the groups with family incomes of more than \$AUS 1199 per week ( $p$ values $<0.05$ ). Odds ratios indicated that the odds of having difficulties in getting to and from food shops of families with income under \$AUS 350 and between \$AUS 350 - \$AUS 799 per week were 6.86 and 6.21 higher, respectively, compared to families with incomes greater than \$AUS 1199 per week.

Regarding the semi-urban/rural areas of residence, the only significant difference between the residents in Dorset and those in Clarence was found to be related to the travel distance between their houses and their most visited food shops. The results of Chi-square tests showed that there was a significant difference $\left(\chi^{2}=165.9, \mathrm{df}=7, \mathrm{p}=.000<0.05\right)$ between the two municipalities, whereby the respondents in Dorset were more likely to live further away from their places of shopping than the respondents in Clarence. However, there were no significant differences in travel difficulties, or financial access between the respondents in Dorset and Clarence.

\section{Discussion}

Findings from the project have identified food insecurity in the municipalities of Dorset and Clarence, which are presented in different forms and at various levels. In terms of physical access to food, nearly one out of ten respondents experienced access difficulties. Around half reported living beyond $5 \mathrm{~km}$ from their most frequently visited food shops necessitating longer travel times and heavier travel costs than those living closer.

A link between physical and financial access was clearly displayed due to the fact that high fuel cost was the most frequently mentioned barrier by those who predominantly used personal vehicles for travelling to and from food shops. This is consonant with current research, which highlights that transport, along with storage and other functional barriers are associated with food insecurity [12, 49]. However, given the reported distances to access preferred food shops, personal transport was the best and in some cases the only choice for many respondents. These findings make a very strong case for wider distribution and incidence of food shops in order to improve access to food. The study also emphasises the need for publicly funded transport systems in order facilitate the acquisition of healthy diets.

Regarding financial access, the most notable finding was the inability to buy nutritious foods at some point during the last 12 months due to lack of finance. Approximately one out of seven residents could not afford nutritious foods at times with their regular income. Serious consideration should be given to prices in order to increase the affordability of nutritious foods. Recognition of this demonstrates that current policies need to be augmented to ensure local food growers, the food industry and retailers are sustainably supported, while equity of access and the promotion of local produce are improved across Tasmania.

Limited physical and financial access also had a connection with inadequate food utilisation among the respondents and that their family members had gone without food because of the shortage of money in the previous 12 months. Many of the respondents experienced food shortages on a frequent basis such as weekly or monthly and these results are similar to those observed in the US [16].

Overall, there were $53(6.6 \%)$ residents were not food secure and 18 (2.1\%) who literally went without food in Dorset and Clarence. The significant correlations between food security and socio-economic factors evidenced in the study are paralleled by other research $[15,16,18,19,50]$. Food-insecure residents were more likely to come from the more vulnerable groups of low income families, the young (less than 25) and old (more than 65) groups, or those living 
in socio-economically disadvantaged rural areas. Consequently, the Australian Government urgently needs to review all income support payments to ensure that they are adequate to allow for an acceptable minimum standard of living for all recipients and retain parity with increases in wages and cost of living.

\subsection{What this Study Adds}

The study reinforces Australia's National Food Plan, which has indicated that access to safe and nutritious food for those living in regional and remote communities remains problematic, particularly among disadvantaged groups and younger people [51]. Further, the study underlines that access and affordability, one of the four priorities outlined the food security strategy "Food for all Tasmanians", remains a key factor for ensuring food security among Tasmanians, particularly in more remote area of the state [37]. This finding is of public health significance, not only for the state of Tasmania but also other Australian states and may also be applicable to rural and remote areas of other countries. The findings contribute to the growing body of literature surrounding food security as a social determinant of health and imply the need for a visionary long term plan, suggesting local and state government develop a more comprehensive strategic approach to food security for the future of Tasmanians.

\subsection{Implications for Policy}

It is recommended that governments, locally and nationally, commit themselves to ensuring that people, particularly those who are dependent on government income support payments, can afford an adequate supply of food that meets the nutrient and energy requirement for all household members. While the choice of where to shop was based on proximity and transport, public transport, such as community cars, that run regularly and that are easy for people to get on and off would be a help for those who do not drive or lack mobility. Thus, we recommend that publicly funded transport systems be promoted wherever possible to support people's capacity to acquire a wide range of healthy food [43]. Further, industries, local government and communities should ensure greater access to nutritious food, particularly among the more remote areas, by promoting local produce and food access initiatives, such as increased farm gate sales, farmer markets, food cooperatives, community gardens and growing and swapping produce within communities.

\subsection{Limitations of the Study}

The study has given some insights into the food security of two rural municipalities of Tasmania. It also has its own limitations regarding the diversity of participants such as ethno-cultural and minority backgrounds and household composition. In addition, as Tasmania is a small island state, it is expected that rural variations are not vastly different as seen in big states such as Western Australian and Queensland. Thus, the choice of Dorset in the south and Clarence in the north could give some representative aspects of rural Tasmania. However, this is also a limitation of the project unless more sites could be included.

\section{Conclusions}

The findings from the project have provided evidence of food insecurity among at least $53(6.6 \%)$ of the residents in the two local government areas of Dorset and Clarence, particularly through limited food access and inadequate food utilisation. A significant correlation was found between aspects of food access and certain socio-economic factors such as income, age groups and semi-urban/rural areas of residence. These findings have added to the evidence over the last decades that some sectors of Australian communities are not food secure, especially the more vulnerable groups from lower socio-economic regions. They have to struggle to feed themselves, predominantly due to physical and financial constraints. The insights into the factors that influence food security obtained from this study will help to direct strategic policies and initiatives to reduce socio-economic barriers to food security. Overall, the study has contributed to reinforcing the evidence base for the implementation of the "Food for all Tasmanians" Strategy by TFSC [37], where access and affordability are highlighted as one of the four priorities. Arguably, the evidence obtained for the socio-economic disparity in food security in Tasmania has given credence to the significance of the 2012 TFSC Strategy, which focuses on ensuring social food equity for all Tasmanians. Future study could focus on frameworks that improve and increase options for people to access nutritious locally available food. This study has shown that a sophisticated understanding of food systems has the potential to contribute and make linkage to future public policy development. Understanding and paying attention to these findings and applying them in future public policy development would be advantageous as the findings are directly applicable to public health.

\section{Acknowledgements}

Members of the Tasmanian Food Access Research Coalition would like to acknowledge Tasmanian Government Department of Premier and Cabinet (DPAC) which provided funding for the TFARC study through the Tasmanian Food Security Council. Coalition members would also like to thank residents of the Dorset and Clarence City Municipal Councils who generously gave their time to participate in the study. Special thanks must also go to the respective Councils of Dorset and Clarence City for assisting with the delivery of the study within their respective municipal council areas. 


\section{REFERENCES}

[1] FAO. Rome Declaration on World Food Security and World Food Summit Plan of Action. In: Summit WF, editor. Rome1996.

[2] FAO. Food security : Concepts and measurement. Trade reforms and food security - Conceptualizing the linkages. Rome: Food and Agriculture Organization of the United Nations; 2003. p. 25-33.

[3] Barrett CB. Measuring Food Insecurity. Science. 2010;327:825-8.

[4] Ecker O, Breisinger C. The food security system - A new conceptual framework: The International Food Policy Research Institute (IFPRI); 2012 [cited 201427 October]. Available from: http://www.ifpri.org/sites/default/files/publi cations/ifpridp01166.pdf.

[5] Apparicio P, Cloutier M, Shearmur R. The case of Montréal's missing food deserts: Evaluation of accessibility to food supermarkets. International Journal of Health Geographics. 2007;6(4):1-13.

[6] Azuma AM, Gilliland S, Vallianatos M, Gottlieb R. Food Access, Availability, and Affordability in 3 Los Angeles Communities, Project CAFE, 2004-2006. Preventing Chronic Disease. 2010;7(2):1-9.

[7] FAO. An introduction to the basic concepts of food security 2008 [cited 201212 February]. Available from: http://www.fao.org/docrep/013/a1936e/a1936e00.pdf.

[8] FAO. Chapter 3: The food system and factors affecting household food security and nutrition: Agriculture and Consumer Protection Department; 1997 [cited 201425 October]. Available from: http://www.fao.org/docrep/W007 8E/w0078e04.htm\#P1642_90314.

[9] Bertrand L, Therien F, Cloutier MS. Measuring and mapping disparities in access to fresh fruits and vegetables in Montreal. Canadian Journal of Public Health-Revue Canadienne De Sante Publique. 2008;99(1):6-11.

[10] Friel S, Baker PI. Equity, food security and health equity in the Asia Pacific region. Asia Pacific Journal of Clinical Nutrition. 2009;18(4):620-32.

[11] Misselhorn A. Is a focus on social capital useful in considering food security interventions? Insights from KwaZulu-Natal. Development Southern Africa. 2009;26(2):189-208.

[12] Temple JB. Household factors associated with older Australian's purchasing a varied diet: Results from household expenditure data. Nutrition \& Dietetics. 2006;63(1):28-35.

[13] Lee JS, Frongillo Jr. EA. Factors Associated With Food Insecurity Among U.S. Elderly Persons: Importance of Functional Impairments. The Journals of Gerontology Series B: Psychological Sciences and Social Sciences. 2001;56(2):S94-S9.

[14] Marshall JA, Lopez TK, Shetterly SM, Morgenstern NE, Baer $\mathrm{K}$, Swenson C, et al. Indicators of nutritional risk in a rural elderly Hispanic and non-Hispanic white population: San Luis Valley Health and Aging study. Journal of the American Dietetic Association. 1999;99(3):315-22.

[15] Quandt SA, Rao P. Hunger and food security among older adults in a rural community. Human Organization. 1999;58(1):28-35.

[16] Nord M, Andrews M, Carlson S. Household Food Security in the United States, 2008. Washington, DC U.S. Department of Agriculture, 2009 November 2009. Report No.: Contract No.: ERR-83.

[17] McCluskey K. Food security in Moreland: A needs assessment. Melbourne: Merri Community Health Services, 2009.

[18] Rychetnik L, Webb K, Story L, Katz T. Food Security Options Paper: A food security planning framework: A menu of options for policy and planning interventions. NSW Centre for Public Health Nutrition, NSW, 2003.

[19] Temple JB. Severe and moderate forms of food insecurity in Australia: are they distinguishable? Australian Journal of Social Issues, The. 2008;43(4):649.

[20] VicHealth. Food Security Fact Sheet. Melbourne: VicHealth, 2007.

[21] Department of Human Services. Victorian population health survey 2006: selected findings. Melbourne: Victorian Government Department of Human Services, Melbourne, Victoria, 2007.

[22] Australian Institute of Health and Welfare. Australia's Health 2010 - The twelfth biennial health report of the Australian Institute of Health and Welfare Canberra: Australian Government, Australian Institute of Health and Welfare; 2010 [cited 201120 September]. Available from: www.aihw.gov.au/WorkArea/DownloadAsset.aspx?id=6442 452962 .

[23] Burns C. A review of the literature describing the link between poverty, food insecurity and obesity with specific reference to Australia. Victoria: Victorian Health Promotion Foundation, 2004.

[24] Outer East Health and Community Support Alliance. Outer East Community - Food Access Research Project: Food Security Assessment and Plans for a way forward. Melbourne: Outer East Health and Community Support Alliance, 2009.

[25] Second Bite. Food Rescue - A Fresh Approach. Report 1 : The social and nutritional impact of fresh rescued food on Victorian community meal programs and their clients: Second Bite; 2011 [cited 201120 September]. Available from: http://secondbite.org/sites/default/files/2011SecondBiteAFre shApproachReport_1_EMAILVERSION.pdf.

[26] Department of Education Employment and Workplace Relations. Labour Market Conditions in Tasmania Hobart: Department of Education, Employment and Workplace Relations; 2013 [cited 201420 october 2014]. Available from: http://employment.gov.au/tasmania-regional-and-industry-e mployment-surveys.

[27] Department of Education Employment and Workplace Relations. Small area labour markets Australia - December quarter 2011 Department of Education, Employment and Workplace Relations: Commonwealth of Australia; 2011 [cited 2012 April 20]. Available from: http://www.deewr.go v.au/Employment/LMI/Documents/SALM_Dec2011.pdf

[28] Australian Bureau Statistics. 2033.0.55.001 - Socio-economic Indexes for Areas (SEIFA) - Table 3. Local Government Area (LGA) Index of Relative Socio-economic Disadvantage 
Canberra: Australian Bureau Statistics; 2011 [cited 201428 October]. Available from: http://www.abs.gov.au/AUSSTAT S/abs@.nsf/DetailsPage/2033.0.55.0012011?OpenDocument

[29] Queensland Health Treasury. The Healthy Food Access Basket Survey 2000. Queensland Health Treasury 2000.

[30] Queensland Health Treasury. The 2006 Health Food Access Basket survey: Queenland Government; 2006 [cited 20118 August]. Available from: http://www.health.qld.gov.au/ph/d ocuments/hpu/33125.pdf.

[31] Meedeniya J, Smith A, Carter P. Food Supply in Rural South Australia: A Survey on Food Cost, Quality and Variety. South Australia: Eat Well SA, 2000.

[32] Department of Health. Food Access and Costs Survey (FACS): Australian Bureau of Statistics and Department of Health, Western Australia 2010 [cited 201120 September]. Available from: http://www.public.health.wa.gov.au/cproot/ 4115/2/Food\%20Access \%20and $\% 20$ Costs $\% 20$ Survey $\% 202$ 010.pdf.

[33] Northern Territory Government. NT Market Basket Survey 2008. Northen Territory: Department of Health and Family, Northen Territory Government 2008.

[34] Madden K. Blue collared: The shrinking world of work in Tasmania. Hobart: Social Action and Research Centre, Anglicare Tasmania, 2003.

[35] Madden K. Bread and Board: when the basics break the budget. Hobart: Social Action and Research Centre, Anglicare Tasmania, 2004.

[36] Tasmanian Government. Tasmanian Food \& Nutrition Policy 20042004 [cited 201028 March]. Available from: http://www.dhhs.tas.gov.au/_data/assets/pdf_file/0014/346 01/TFNP_final.pdf.

[37] Tasmanian Food Security Council. Food for all Tasmanians A food security strategy. Tasmanian Food Security Council; 2012.

[38] Australian Bureau Statistics. 2011 Census Quick Stats Tasmania: Australian Bureau Statistics; 2011 [cited 201425 October]. Available from: http://www.censusdata.abs.gov.au /census_services/getproduct/census/2011/quickstat/6?opendo cument $\&$ navpos $=220$.

[39] Australian Bureau Statistics. 2006 Census of Population and Housing Canberra: Australian Bureau of Statistics; 2006 [cited 200819 June]. Available from: http://www.abs.gov.au/.

[40] Department of Health and Human Services. Department of Health and Human Services - Service and Community Profile: Clarence Local Government Area Profile: Department of Health and Human Services; 2009 [cited 201030 August].
Available from:http://www.dhhs.tas.gov.au/_data/assets/pd f_file/0006/48219/2009_Clarence_LGA_profile.pdf.

[41] Australian Bureau Statistics. Census of Population and Housing: Socio-Economic Indexes for Areas (SEIFA), cat. 2033.0.55.001. 2008 [cited 2012 April 20]. Available from: http://www.abs.gov.au/AUSSTATS/abs@.nsf/DetailsPage/2 033.0.55.0012006? OpenDocument.

[42] Department of Health and Human Services. Department of Health and Human Services - Service and Community Profile: Dorset Local Government Area Profile: Department of Health and Human Services; 2009 [cited 201030 August]. Available from:

http://www.dhhs.tas.gov.au/_data/assets/pdf_file/0018/482 22/2009_Dorset_LGA_profile.pdf.

[43] Le Q, Murray S, Long G, Auckland S, Etchells T, Flanagan J, et al. Tasmanian food access research coalition TFARC: Research report. Hobart: Tasmanian Food Access Research Coalition, 2013.

[44] National Health and Medical Research Council. Dietary Guidelines for Australians. Canberra: National Health and Medical Research Council, Australian Government Publishing Services, 2003.

[45] National Health and Medical Research Council. Australian Dietary Guidelines. Canberra: National Health and Medical Research Council, 2013.

[46] ABS. National Nutrition Survey Selected Highlights Australia 1995, Cat No 48020, Commonwealth Government Canberra: Australan Bureau of Statistics; 1995 [cited 201031 August]. Available from: http://www.ausstats.abs.gov.au/aus stats/free.nsf/0/236465EA4E9B3D2BCA25722500049629/\$ File/48020_1995.pdf.

[47] CHOICE. Do I need a landline? Marrickville, New South Wales: CHOICE; 2011 [cited 201225 July]. Available from: http://www.choice.com.au/reviews-andtests/technology/phon es-and-mobile-devices/home-phones/do-you-need-a-landline .aspx.

[48] Flanagan K. Hard times: Tasmanians in financial crisis. Hobart: Tasmania Anglicare, 2010.

[49] Temple JB. Food insecurity among older Australians: prevalence, correlates and well-being. Australasian Journal on Ageing. 2006;25(3):158-63.

[50] Williams PG. Monitoring the affordability of healthy eating: a case study of 10 years of the Illawarra Healthy Food Basket. Nutrients. 2010;2(1):1132-40.

[51] Department of Agriculture Fisheries and Forestry. National Food Plan - Our food future. In: Department of Agriculture $\mathrm{FaF}$, editor. Canberra2013. 